\title{
Gender Differences in Perceptions of Conventional Video, Virtual Reality and Augmented Reality
}

\author{
https://doi.org/10.3991/ijim.v13i06.10487 \\ Amir Dirin ${ }^{(凶)}$, Ari Alamäki, Jyrki Suomala \\ Haaga-Helia University of Applied Sciences, Helsinki, Finland \\ amir.dirin@haaga-helia.fi
}

\begin{abstract}
The user's emotional involvement plays an important role in adopting new technologies. The level of engagement with and adoption of new digital applications depends on various personal, contextual, and emotional factors. In our study, we assessed the personal factors, such as gender differences, of perceiving and adopting technologies such as virtual reality (VR), augmented reality (AR), and conventional video. Furthermore, we assessed what kind of emotions are involved in and invoked by the context of new technologies. This is a quantitative study in which students were asked to perform experiments on $\mathrm{VR}, \mathrm{AR}$, and conventional videos. After the experiments, participants were asked to fill out a predefined survey about their emotional reactions to the experiments. The results show, unlike the prior research, that female participants were more enthusiastic about the usage of new technologies than males. The user experience of VR, AR and conventional videos triggered more positive emotions among females than males. For practitioners, the results suggest that the audio-visual technologies could engage more females than males. For academics, this study provides further research on how to trigger users to adopt new audio-visual technologies.
\end{abstract}

Keywords-Virtual Reality, Augmented Reality, Conventional Video, User Experience

\section{Introduction}

People have different desires and preferences when choosing new smart gadgets to use. These desires are mainly rooted in gender, personality, interest, values, and social setup (Etkin \& Sela, 2014). Therefore, the design and development of a robust application mandates that these issues be investigated thoroughly. Furthermore, the popularity of mobile devices and the significant technological advancement in recent years have made these devices central tools in various fields, including in the marketing sector.

Therefore, primitive advertisement approaches, such as using posters to promote products, no longer cover a wide audience (Dennis, Joško Brakus, \& Alamanos, 2013). This is rooted into two main reasons. First, primitive advertisement does not draw the attention of a digital audience (Marciniak, 2014). Second, the new digital 
generations prefer to use their mobile devices for most activities, including consuming advertisements, despite its occasional inconvenience. The demands and needs of advertising have shifted from traditional media to digital content presentation. To promote new services for the aforementioned generations, the designers must anticipate the needs of the users' segments and their emotional engagement factors.

Smart gadgets such as smartphones are continuously expanding and extending their reach with advanced technologies such as virtual reality (VR) and augmented reality (AR). VR and AR technology has been utilized in various industries for more than two decades. Their popularity has rapidly increased as VR and AR applications have become feasible in smart gadgets like smart phones (Mazuryk, Gervautz, \& Smith, 2013). For example, VR and AR are now used in educational environments (Hussein \& Nätterdal, 2015), in psychotherapy (Diemer, Pauli, \& Mühlberger, 2015), and in tourism (Guttentag, 2010). Less than two decades ago, VR and AR applications were feasible only behind closed doors with dedicated laboratories and powerful computers for testing and experimentation. Smart phones have shifted the application of VR and AR from laboratories to people's pockets. However, those who are skeptical of new technologies are still cautious when it comes to experimenting with new technologies such as AR and VR.

This study aims to reveal how new generations feel about using these technologies on a daily basis. Furthermore, we want to clarify whether there are gender differences in emotional perceptions of new technology. The results of this study will help the designers of $\mathrm{VR}$ and $\mathrm{AR}$ to consider the proper design approach for providing content in new technologies.

\section{Related Studies}

Research into gender differences in the use of VR and AR technologies is scant, but prior research on gender differences in the use of mobile technologies provide some insight into the phenomenon. Hamza and Shah (2014) found that males had higher perceived ease of use than the females when using mobile technology, while social norms influenced the female students more than the males in adopting mobile payment methods. They did not, however, find significant differences in the general adoption of mobile payment systems between genders. Wood and Li (2005) found that males were more willing to adopt new technologies than females. They studied differences by using the model of a technology adoption curve. They found that gender affects one's behavioral intention to use mobile internet, but not in all cases. Wang and Wang (2010) found that the effect of performance expectancy, in other words, expected benefits to job performance from the usage of mobile internet, was a stronger determinant of adoption for male users, whereas effort expectancy, which refers to ease of use, was significant for females. In investigating the adoption of mobile banking, Riquelme and Rios (2010) found that ease of use has a stronger effect on female users than male users, whereas the male users were more affected by perceived usefulness. The female users were more impacted by social norms, which means that they were more likely to involve others in decision-making. Kongaut and 
Bohlin (2016) did not find differences between Swedish males and females in the use of mobile applications, except that males were more active online ticket shoppers, whereas females used more social-media applications. Li, Glass, and Redords (2008) studied gender differences in the adoption and use of mobile commerce services. They did not find significant differences between males and females, as the adoption rates and adopted stage patterns were similar. The only difference that they found was in the use of communication, information, and transaction services, in which males were more active. They concluded that males probably move through the adoption stages faster than females. From the viewpoint of mobile usage, males moving faster through adoption stages of mobile commerce services would suggest some differences in the use of VR and AR as well.

Studies of gender differences in the acceptance of new technologies are not new. For example, Wang and Wang (2008) conducted a study on the gender differences in perceiving the playfulness of an online game. Venkatesh, Morris, and Ackerman (2000) conducted a study to investigate the gender differences in individual technology adoption decision-making processes. Their findings indicate that men are more strongly inclined to use new technology. Goswami and Dutta (2016) conducted a literature review on the gender differences in the use of new technologies in various domains, such as education, banking, health care etc. Their findings reveal that gender has a significant impact on the intention to accept new technology.

Companies apply various approaches to promote their products to consumers. Traditionally printed media were the main source of promotion, but in recent years, the popularity of smart devices has caused the promotion of new products to shift toward new methods such as text, audio, and video delivered to people's pockets. In the latest wireless technologies advances such as AR and VR, consumers are enabled to engage emotionally with their applications, especially in tourism industries. AR (Sowmya, Parthipan, \& Sriram Kumar, 2015) and VR (Negrotti, 2012) have been around for more than two decades. The applications of these technologies were mainly implemented behind closed doors and with Personal Computers (Li, Yi, Chi, Wang, \& Chan, 2018). However, in recent years, VR and AR have become also enabled on smart devices. Furthermore, 360 degree video clips (Corbillon, Simon, Devlic, \& Chakareski, 2017) have also become feasible as a panorama view in smartphones.

Outdoor activities in Finland are very popular (Alamäki \& Dirin, 2015). The activities that the outdoor services' providers offer cover a wide range of entertainment and sports services. They often promote their services both to national and international customers. To promote outdoors activities, the authors have conducted much research in this field, and some of the research results have been published in international journals such as (Alamäki, Dirin, Huotari, \& Korhonen, 2016), and (Alamäki \& Dirin, 2014). Nature in every country has its own tourism industry, and often governments promote nature to tourists through advertisements. Geffroy, Samia, Bessa, and Blumstein (2015) conducted a global study on trends in nature-based tourism that indicated a decline in the number of nature-based tourists globally. Therefore, various attempts have been made to tackle this decline. For example, Wood, Guerry, Silver, and Lacayo (2013) have used social media to increase nature-based tourism. They 
shared photos to Flickr and then traced who, when, and which countries had visited the photos; they then collected this information and aggregated it as big data.

\section{$3 \quad$ Research Methodology and Processes}

\subsection{Research questions}

In this study, we conducted an experiment with students of various degree programs. After each experiment, students were asked to fill out a hardcopy survey. The aim of this study was to investigate gender differences in user experiments with video, VR, and AR. This study aims to answer the following research question:

Is there a relationship between gender and user experiments with video, VR, and AR?

\subsection{Participants}

This is quantitative research that we have conducted with students in the Information Technology and in Tourism Management degree programs. The participants were of various nationalities and were both male $(n=61)$ and female $(n=39)$. The age of the students varied between 19 and 34 years old.

\subsection{Data gathering}

In each experiment, we prepared and printed a survey and handed it to students. After the survey, we compared the females' and males' differences in their emotional reactions using independent $\mathrm{t}$-tests.

The students were instructed to execute the experiments either individually or in a group of two or three members. The task order and the instructions were given as follows:

- Access and watch the conventional videos

- The access, use and watch 360 videos by using VR classes

- Download the Arilyn AR application, scan the target image and interact with the AR virtual object

- Answer the questionnaire independently

The test users were able to test the experiments either on PCs or on smartphones. We provided a barcode for the experiment applications to make the experiment fast and easy for students. The content in the videos, VR and AR were marketing material and originally designed for marketing purposes. This created the same type of content for all experiments. Figure 1 shows an example of AR application. 


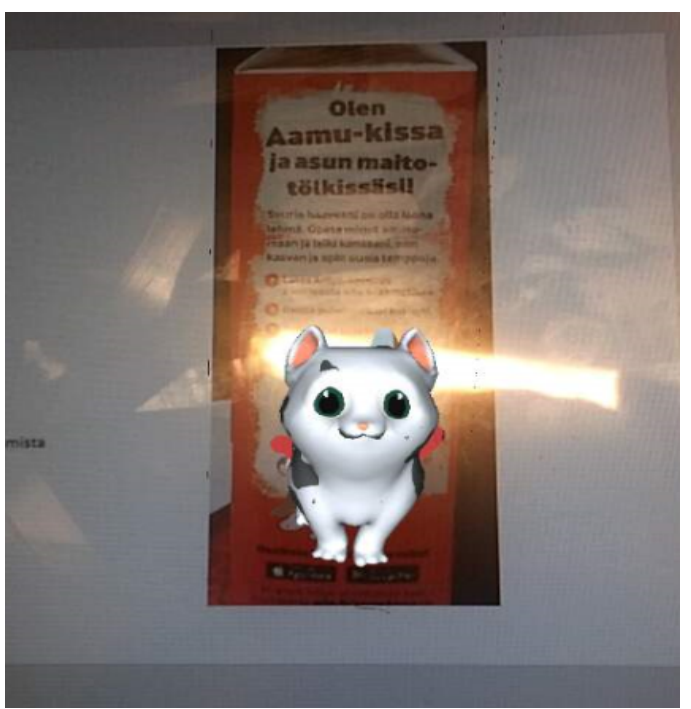

Fig. 1. Sample of the AR object that pop-upped from the target image.

We have collected a significant amount of data, but in this paper, the focus is on gender difference in perceptions and behaviours of participants towards video, VR, and AR. In the survey, we asked students their age, nationality, study year, previous knowledge of the VR and AR experiment, and their emotional experience of the experiment. The sample questionnaire that we utilized in this study is shown in Figure 2. For each emotional word, the statement was translated into numeric values $(5=$ fully agree, 4 = agree, 3 = neutral, 2 = disagree, $1=$ completely disagree) for statistical analyses.

\section{Please choose the option after each emotional word that best describe your emotion during the} experiment
1. Relaxing
2. Inspiring
3. Encouraging
4. Exciting
5. Unpleasant
6. Depressing
7. Boring

[ ] fully agree, [ ] agree, [ ] neutral, [ ] disagree, [ ] completely disagree [ ] fully agree, [ ] agree, [ ] neutral, [ ] disagree, [ ] completely disagree [ ] fully agree, [ ] agree, [ ] neutral, [ ] disagree, [ ] completely disagree [ ] fully agree, [ ] agree, [ ] neutral, [ ] disagree, [ ] completely disagree [ ] fully agree, [ ] agree, [ ] neutral, [ ] disagree, [ ] completely disagree [ ] fully agree, [ ] agree, [ ] neutral, [ ] disagree, [ ] completely disagree [ ] fully agree, [ ] agree, [ ] neutral, [ ] disagree, [ ] completely disagree

Fig. 2. Sample questionnaire that students were asked to complete.

For the AR experiments, we did not develop any new application but instead used Arilyn ("Arilyn," 2019) and Arla's (“Arla," 2019) joint AR product. Students were asked to scan a cat figure in a milk packet and determine whether they could see a live cat on their smartphone's screen. 


\subsection{Data analysis}

The data set consisted of 100 completed questionnaires. The data analysis was conducted with IBM ${ }^{\circledR}$ SPSS ${ }^{\circledR}$ Statistics. The values of the variables in the Figure 2 were encoded so that the more the participant agreed with the statement, the greater the value of it is (i.e. fully agree $=5$; complete disagree $=1$ ).

\section{$4 \quad$ Result}

Table 1 presents students' perspective based on the emotional terms used in the survey for normal video, VR, and AR. The sample size was 100 , of which $n=61$ were male and $n=39$ were female. SPSS ignored the values that have not been provided in the table. We collected a significant amount of data during the experiment; however, in this study, we only present the gender differences concerning the three aforementioned technologies. Table 1 presents the independent sample test of the gender differences collected through the questionnaire during the experiments.

Table 1. Independent sample test of the gender differences

\begin{tabular}{|c|c|c|c|c|c|c|c|c|}
\hline \multirow{2}{*}{$\begin{array}{l}\text { Technology } \\
\text { Conventional video } \\
\end{array}$} & \multirow[t]{2}{*}{ Emotion } & \multicolumn{2}{|c|}{ Female } & \multicolumn{2}{|c|}{ Male } & \multirow[t]{2}{*}{ t-value } & \multirow[t]{2}{*}{$\mathbf{d f}^{\mathbf{1}}$} & \multirow[t]{2}{*}{ sig. } \\
\hline & & $x$ & sd & $x$ & sd & & & \\
\hline & Inspiring & 3.56 & 0,72 & 3.218 & 0,83 & $-2,19$ & 95 & $\mathrm{p}<0,05$ \\
\hline \multicolumn{9}{|l|}{360 Video } \\
\hline & Boring & 1.92 & 0,10 & 2.555 & 1,25 & -2.75 & 91.02 & $\mathrm{p}<0,01$ \\
\hline & Depressing & 1.58 & 0,68 & 2.15 & 0,10 & $-3,11$ & 95 & $\mathrm{p}<0,01$ \\
\hline & Exciting & 3.84 & 0,92 & 3.42 & 1,12 & 2,01 & 95 & $\mathrm{p}<0,05$ \\
\hline & Inspiring & 3.95 & 0,73 & 3.56 & 1,05 & 2,20 & 23.43 & $\mathrm{p}<0,05$ \\
\hline \multicolumn{9}{|l|}{ Augmented Reality Video } \\
\hline & Boring & 2.08 & 1,15 & 2.69 & 1,29 & $-2,37$ & 94 & $\mathrm{p}<0,05$ \\
\hline & Depressing & 1.68 & 0,84 & 2.12 & 1,11 & $-2,07$ & 94 & $\mathrm{p}<0,05$ \\
\hline & Unpleasant & 1.73 & 0,80 & 2.21 & 1,02 & $-2,40$ & 93 & $\mathrm{p}<0,05$ \\
\hline & Exciting & 3.65 & 0,95 & 3.13 & 1,16 & 2,40 & 94 & $\mathrm{p}<0,05$ \\
\hline
\end{tabular}

\subsection{Conventional Video Clip}

Statistically, females $(\mathrm{n}=39)$ felt that the conventional video was more inspirational $(\mathrm{x}=3.56 ; \mathrm{sd}=0.72)$ than males $(58)$ did $(\mathrm{x}=3.22 ; \mathrm{sd}=0.83), \mathrm{t}(95)=-2,187, \mathrm{p}<$ $.05)$.

\subsection{Video using VR glasses}

Females $(\mathrm{n}=38)$ felt that the 360 video was statistically less boring $(\mathrm{x}=1.92$; $\mathrm{sd}=$ $0.10)$ than males $(\mathrm{n}=60) \operatorname{did}(\mathrm{x}=2.56 ; \mathrm{sd}=1.25), \mathrm{t}(91,02)=-2,75, \mathrm{p}<.01$.

In addition, females $(\mathrm{n}=38)$ felt that the 360 video was statistically less depressive $(\mathrm{x}=1.58 ; \mathrm{sd}=0.68)$ than males $(\mathrm{n}=59) \operatorname{did}(\mathrm{x}=2.15 ; \mathrm{sd}=0,10), \mathrm{t}(95)=-3,11, \mathrm{p}<$ .01 . 
Similarly, females $(\mathrm{n}=38)$ felt that the 360 video was statistically more exciting ( $\mathrm{x}$ $=3.84 ; \mathrm{sd}=0,92)$ than males $(\mathrm{n}=59)$ did $(\mathrm{x}=3.42 ; \mathrm{sd}=1,12), \mathrm{t}(95)=2.01, \mathrm{p}<.05$.

Furthermore, females $(n=38)$ considered the 360 video to be statistically more inspiring $(\mathrm{x}=3.95 ; \mathrm{sd}=0.73)$ than males $(\mathrm{n}=59)$ did $(\mathrm{x}=3.56$; $\mathrm{sd}=1,05), \mathrm{t}(23.43)=-$ $2,20, p<.05$. Finally, in the answer to the question about the intention of participants to share the 360 video, females $(\mathrm{n}=38)$ showed statistically more intention to share the 360 video $(\mathrm{x}=3.53 ; \mathrm{sd}=1.08)$ than males $(\mathrm{n}=61)$ did $(\mathrm{x}=2.97$; $\mathrm{sd}=1,224)$, $\mathrm{t}(97)=2,31, \mathrm{p}<.05$.

\subsection{Augmented Reality Experiment}

The question concerning perceptions that AR is boring showed that females $(\mathrm{n}=38)$ felt that the AR video was statistically less boring $(\mathrm{x}=2.08$; $\mathrm{sd}=1.15)$ than males $(\mathrm{n}$ $=58) \operatorname{did}(\mathrm{x}=2.69 ; \mathrm{sd}=1.29), \mathrm{t}(94)=-2,37, \mathrm{p}<.05$. Aligned with this is the finding that females $(\mathrm{n}=38)$ felt that the AR video was statistically less depressive $(\mathrm{x}=1.68$; $\mathrm{sd}=0.84)$ than males $(\mathrm{x}=58)$ did $(\mathrm{x}=2.12 ; \mathrm{sd}=1,11), \mathrm{t}(94)=2,07, \mathrm{p}<.05$. Additionally, females $(\mathrm{n}=37)$ felt that the AR video was statistically less unpleasant $(\mathrm{x}=$ $1.73 ; \mathrm{sd}=0.80)$ than males $(\mathrm{n}=58)$ did $(\mathrm{x}=2.21 ; \mathrm{sd}=1.02), \mathrm{t}(93)=-2.40, \mathrm{p}<.05$. Furthermore, females $(\mathrm{n}=37)$ felt that the AR video was statistically more exciting ( $\mathrm{x}$ $=3.65 ; \mathrm{sd}=0.95)$ than males $(\mathrm{n}=59) \operatorname{did}(\mathrm{x}=3.13 ; \mathrm{sd}=1.16), \mathrm{t}(94)=-2,40, \mathrm{p}<.05$.

Overall the females experiences about the conventional video, the 360 video and AR-application were more positive than male's experiences.

\section{Discussion}

The aim of this study was to examine students' experiences with normal video, VR, and AR application usage. Furthermore, we aimed to study gender differences in emotional perceptions of new technology use. In addition, through this study, we tried to elaborate the students' preferences regarding video, AR, and VR technology use rather than the content of the selected technologies.

Among all participants, females considered conventional video more inspiring than males. Aligned with this is the finding that female participants considered the VR to be more inspiring than males. On the other hand, male participants considered the 360 video to be more boring, less exciting, and more depressing than females. The main reason for the result is that the 360 clip mandates that the user wear VR glasses, which are often associated with many challenges (Guttentag, 2010). This result, surprisingly, is similar in the AR experiment. Males identified the AR as more unpleasant and depressive, and less exciting than females.

The findings are not align with the research of Wood and Li (2005), who found that males were more willing to adopt new technologies than females. They concluded that males probably move through adoption stages faster than females, which is not substantiated by this study. However, our findings partly align with the studies of Kongaut and Bohlin (2016) and Li, Glass, and Redords (2008), who did not find significant gender differences in mobile technology adoption. Wang and Wang (2010) and 
Riquelme and Rios (2010) found that the ease of use of new technology was a stronger determinant of adoption for females than for males. This finding is interesting from the perspective of this study, as VR and AR are not necessarily easy to use. In particular, VR glasses are difficult to use for the first time, and many users do not know how to set them up. Thus, gender differences in the use of VR and AR merit further research. The use of VR and AR does not involve just browsing web content or clicking mobile apps, but it requires several interactive steps. In using VR glasses with their smartphones, users need to find a 360 video, click the cardboard-icon, and pair the smartphone to the VR glasses. While using an AR application, users need to download the right mobile app to scan the target and be able to get content to jump out from the screen. This study suggests that adapting VR and AR applications to the educational context would require a special focus on technical support and ease of use.

The results indicate that there are significant differences in male and female perception of new technology use. Female students show more interest in new technology use and experimentation. A previous study (Saballe, Le, \& Dirin, 2018) has demonstrated that these experiments themselves change perceptions. We asked the participants to evaluate how different emotional concepts illustrate their emotional reactions in using conventional videos, VR and AR application. The findings show, unlike the prior research (e.g. Kongaut \& Bohlin, 2016; Li, Glass \& Redords, 2008; Wood \& $\mathrm{Li}, 2005)$, that the videos, VR and AR caused more positive emotional responses to females than males. The emotional response to the new technology is important in adopting new technology to various purposes. Thus, the findings contribute to the many fields where the positive user experience is essential for the successful implementation. The digital service designer and marketers can utilize findings in designing VR and AR services that are targeted to the female customers. In addition, the findings suggest that females would prefer audio-visual and interactive technologies that could be an important knowledge in the career selection debate. The females may also prefer more VR and AR applications than other digital applications creating a new potential channel for marketers, educators, game developers and administrators to deliver and sell digital content and services.

\section{Conclusion}

This study has demonstrated that gender impacts the adoption of new technologies. This study does not confirm previous general findings about male capabilities to adopt new technologies. In our study, we found that females adopt AR applications, VR applications, and conventional video clips faster than male participants.

The findings of this study are only valid in the context in which we conducted the study, so it is not feasible to draw a general conclusion. Furthermore, in this study, we were not able to assess what types of triggers the participants evaluated, the special features of tools or the digital content elements. This could have been clarified by conducting a follow-up study - for example, with interviews. Hence, we plan to extend the study with more participants in order to validate its findings. 


\section{$7 \quad$ Acknowledgements}

We would like to thank the Virtual Outdoors project (funded by EU agricultural and rural development fund) for the opportunity to conduct research in this field.

\section{References}

[1] Alamäki, A., \& Dirin, A. (2014). Designing Mobile Guide Service for Small Tourism Companies Using User Centered Design Principle. In Proceedings of the International Conference on Computer Science, Computer Engineering, and Social Media, Thessaloniki, Greece, 2014 (pp. 47-58).

[2] Alamäki, A., \& Dirin, A. (2015). The stakeholders of a User-Centered Design Process in Mobile Service development. International Journal of Digital Information and Wireless Communications, 5(4), 270-284. https://doi.org/10.17781/p001825

[3] Alamäki, A., Dirin, A., Huotari, J., \& Korhonen, N. (2016). Rapid Prototyping of A Mobile SAAS Application. Journal of Mobile Multimedia, 12(1), 138-158.

[4] Arilyn. (2019). Retrieved from https://arilyn.com/

[5] Arla. (n.d.). Retrieved from https://www.arla.fi/

[6] Corbillon, X., Simon, G., Devlic, A., \& Chakareski, J. (2017). Viewport-adaptive navigable 360-degree video delivery. In IEEE International Conference on Communications. https://doi.org/10.1109/icc.2017.7996611

[7] Dennis, C., Joško Brakus, J., \& Alamanos, E. (2013). The wallpaper matters: Digital signage as customer-experience provider at the Harrods (London, UK) department store. Journal of Marketing Management. https://doi.org/10.1080/0267257x.2013.766628

[8] Diemer, J., Pauli, P., \& Mühlberger, A. (2015). Virtual Reality in Psychotherapy. In International Encyclopedia of the Social \& Behavioral Sciences: Second Edition. https://doi.org/10.1016/b978-0-08-097086-8.21070-2

[9] Etkin, J., \& Sela, A. (2014). How Experience Variety Shapes Post-Purchase Product Evaluation. SSRN. https://doi.org/10.2139/ssrn.2467780

[10] Geffroy, B., Samia, D. S. M., Bessa, E., \& Blumstein, D. T. (2015). How Nature-Based Tourism Might Increase Prey Vulnerability to Predators. Trends in Ecology and Evolution. https://doi.org/10.1016/j.tree.2015.09.010

[11] Goswami, A., \& Dutta, S. (2016). Gender Differences in Technology Usage-A Literature Review. Open Journal of Business and Management. https://doi.org/10.4236/ojbm.2016.41006

[12] Guttentag, D. A. (2010). Virtual reality: Applications and implications for tourism. Tourism Management. https://doi.org/10.1016/j.tourman.2009.07.003

[13] Hussein, M., \& Nätterdal, C. (2015). The Benefits of Virtual Reality in Education: A Comparison Study. University of Gothenburg, Chalmers University of Technology. https://doi.org/10.1177/0011000003253155

[14] Li, X., Yi, W., Chi, H. L., Wang, X., \& Chan, A. P. C. (2018). A critical review of virtual and augmented reality (VR/AR) applications in construction safety. Automation in Construction. https://doi.org/10.1016/j.autcon.2017.11.003

[15] Marciniak, R. (2014). "Born Digital Understanding The First Generation Of Digital Natives? Systèmes d'information \& Management. https://doi.org/10.3917/sim.102.0128 
[16] Mazuryk, T., Gervautz, M., \& Smith, K. (2013). Virtual Reality History, Applications, Technology and Future. Digital Outcasts. https://doi.org/http://dx.doi.org/10.1016/B978-012-404705-1.00006-6

[17] Negrotti, M. (2012). Virtual reality. In Studies in Applied Philosophy, Epistemology and Rational Ethics. https://doi.org/10.1007/978-3-642-29679-6_22

[18] Saballe, C., Le, H., \& Dirin, A. (2018). EXPERIENCE CḦANGES THE PERCEPTION AND FEELINGS: A CASE STUDY ON MVR APPLICATION IN EDUCATIONAL CONTEXT. In 10th annual International Conference on Education and New Learning Technologies 2n4-4th of JUly. 2018. Palma de Mallorca (Spain). https://doi.org/10.21125/edulearn.2018.2481

[19] Sowmya, V., Parthipan, V., \& Sriram Kumar, V. (2015). Augmented reality. International Journal of Applied Engineering Research. https://doi.org/10.1109/TVCG.2015.2408612

[20] Venkatesh, V., Morris, M. G., \& Ackerman, P. L. (2000). A Longitudinal Field Investigation of Gender Differences in Individual Technology Adoption Decision-Making Processes. Organizational Behavior and Human Decision Processes. https://doi.org/10.1006/obhd.2000.2896

[21] Wang, H. Y., \& Wang, Y. S. (2008). Gender differences in the perception and acceptance of online games. British Journal of Educational Technology. https://doi.org/10.1111/j.1467-8535.2007.00773.x

[22] Wood, S. A., Guerry, A. D., Silver, J. M., \& Lacayo, M. (2013). Using social media to quantify nature-based tourism and recreation. Scientific Reports. https://doi.org/10.1038/srep02976

\section{Authors}

Amir Dirin has a PhD in usability engineering from Aalto University in Finland. He is a principal lecturer in Business Information Technology Department at the Haaga-Helia University of Applied Sciences. Amir has strong research background in mobile learning application design \& development e.g., AR/VR/XR learning, adaptive learning, usability, and user experience of mobile learning application design and development.

Ari Alamäki received a $\mathrm{PhD}$ in technology education in 1999, and currently he is a principal lecturer at Haaga-Helia University of Applied Sciences, Finland. His current research focuses on customer behavior in digital channels, digital tourism marketing, and business perspectives on big data analytics. His work has been published in both refereed scientific journals and practically oriented business journals and books. He also has over 12 years of experience in business consulting and software development. E-mail: ari.alamaki@haaga-helia.fi

Jyrki Suomala is an adjunct professor, Principal Lecturer Jyrki Suomala (born 1959) has over 24 years of research experience at the universities in Finland. In addition, he has been a visiting researcher at the University of California at Santa Barbara for a total period of three and half years. His main research interest is human's decision making and choice in different contexts. Suomala applies cognitive science, behavioral economics and decision neuroscientific approach to his research projects. He has participated in various research projects funded by the Academy of Finland (UCRET project, 1996-2001; SOCA, 2003-2007) and the Ministry of Education 
(STEMA project). He was principal investigator of NeuroService -project funded by TEKES, in which his research group study the neurophysiological and behavioral responses of consumers in the different authentic marketing messages by fMRI. He obtained his Ph.D. on Education in 1999 from the University of Jyväskylä (Finland).He has published articles in international peer-refereed journals such as European Journal of Innovation Management and Journal of Educational Computing Research, Technology Innovation Management. He has established a new NeuroLab at Laurea University of Applied Sciences. He is currently studying neurophysiological and behavioural basis of human decision making and choice in different contexts. (email: jyrki.suomala@laurea.fi)

Article submitted 2019-03-15. Resubmitted 2019-04-03. Final acceptance 2019-04-04. Final version published as submitted by the authors 